\title{
Ueber die Einwirkung von Luft und Wärme auf den Gerbstoff
} der Weidenrinde haben W. Sonne und Fr. Kutseher*) eine ausführliche Arbeit veröffentlicht, deren Resultate sie in folgender Weise zusammenfassen.

Der Weidenrindengerbstoff erleidet sowohl bei dem Erhitzen seiner wässrigen Lösung ohne Volumverminderung, wie auch beim Concentriren eine theilweise Zersetzung. Die Grösse derselben hängt hauptsächlich von der Höhe der beim Erhitzen, respective Eindampfen, herrschenden "Temperatur ab. Der Sauerstoff der Luft wirkt hierbei allerdings auch zersetzend ein, jedoch nur in geringem Grade.

Im Uebrigen muss ich auf die Originalarbeit verweisen.

2. Quantitative Bestimmung organischer Körper.

\section{a. Elementaranalyse.}

Zur Kjeldahl'schen Stickstoffbestimmungsmethode. Otto Schönherr**) und M. Saugeron ${ }^{* * *}$ ) haben unabhängig von einander vorgeschlagen, das bei der Behandlung mit Schwefelsäure gebildete Ammoniak mit Hülfe des Azotometers zu bestimmen. Zu diesem Zweck wird der Aufschluss der Substanz wie gewöhnlich bewirkt. Nach dem Erkalten wird verdünnt, neutralisirt, auf ein bestimmtes Volumen aufgefüllt und ein entsprechender Theil zur azotometrischen Bestimmung benutzt.

Georg Roch $\dagger$ ) empfiehlt zur Destillation eine tubulirte, mit dem Halse aufwärts gerichtete Retorte, an welche eine knieförmig gebogene, engere Glasröhre mittelst eines Korkstopfens angesetzt ist. Als Vorlage dienen zwei Erlenmeyer'sche Kölbchen, die durch ein in beiden Fläschchen bis fast auf den Boden reichendes, zweimal rechtwinklig gebogenes Glasrohr mit einander in Verbindung stehen. Da diese Vorlage eventuell in kaltes Wasser gestellt werden kann, so ist die Anwendung eines Kühlers nicht nöthig.

B. †) führt an, dass die Jodlbau er'sche †††) Methode der Behandlung mit Phenol enthaltender Schwefelsäure bei salpeterhaltigen Stoffen nicht

*) Zeitschrift f. angew. Chemie 1889, s. 508.

**) Chemiker-Zeitung 12, 217.

***) Arch. de Pharm. 3, 1; durch Analyst 13, 116.

†) Pharm. Centralhalle [N. F.] 10, 48.

††) Chemisches Centralblatt [3. F.] 19, 557.

††) Vergl. diese Zeitschrift 26, 92. 